\title{
Modification of the Network Model When Implementing the Project Approach
}

\author{
Maksim Kocherian, Andrey Plakhin*, Irina Vashliaeva, Tatiana Volovik, and \\ Elena Davydova
}

Ural State University of Economics, 620144 Ekaterinburg, Russia

\begin{abstract}
The relevance of the research is due to the need to determine the effectiveness of the project approach from the point of view of network interaction. The purpose of the article is to test the method of network management of physical culture and sports activities of the University developed by the authors within the project approach. The implementation of the project approach has led to increased coverage and an increase in the number of stable connections in the network model. The network model is transformed from a concentric type to a distributed one by increasing the number of projects with active participation of Universities. In the scheme of network interaction, there are connections due to the need to ensure the implementation of training courses, in particular for FSBEI HE USUE connections appear to overcome resource constraints. Much more active is the inclusion of the physical culture and sports activities in projects initiated by state and municipal authorities, the corporate sector, sports organizations and Universities themselves. The number of participants actively using the network strategy has increased.
\end{abstract}

\section{Introduction}

The project approach has proven its effectiveness in many areas of human activity. The term project ("projectus") originally meant protruding forward or protruding. Since the midfifties of the twentieth century, the project has become a concept that describes a set of interrelated actions aimed at achieving a specific goal in a limited period of time and limited resources. In management theory, the project is described as one of the most effective management tools, which, thanks to the aggregation of all management functions relative to one object, allows you to get the intended results.

The database of research works contains a large number of studies on the use of project approach in various spheres of human activity. So, the article by S. M. Markova and E. P. Sedych [1] states that "Project management is the most important factor in the development of educational systems; it is a universal scientific process, carrying out the formulation and implementation of the innovative goals of the formation of advanced thinking, system design actions, design culture, which are crucial in professional education." Regarding the use of the project approach in the field of physical culture and sports management, O. V. Skopin notes [2] that the features of the project approach consist in the continuity of projects that are

\footnotetext{
*Corresponding author: apla@usue.ru
} 
determined not so much by the implementation technology as by common resources, common structures and works. Combining individual projects into a system - "portfolio" allows you to get an additional effect from their joint, coordinated implementation on a common technological and resource base. The need to use the project approach in the management of physical culture and sports activities is justified in the works of E. V. Nesterova [3], A. N. Dubakin [4]. Using the project approach allows you to overcome the limitations imposed by the functional management system of physical culture and sports activities in higher education organizations, formalize planning procedures, optimize resources, and evaluate the effectiveness of events. The role of the project approach in the network strategy of physical culture and sports activities of the University is to use the developed methodology of project management to streamline the diverse relationships that arise in the network interaction of subjects.

However, while agreeing with the above provisions, it is necessary to supplement the positive effects of using the project approach within the network strategy of physical culture and sports activities of the University with the following provisions. From the point of view of management, the use of the project approach allows achieving the following effects:

- to structure a network of independent entities primarily due to the ability to assess the priority of projects by using sets of indicators;

- to stabilize the roles (organizational, coordinating, providing) of network entities, laying them down in the relevant project documentation;

- to make a comprehensive assessment of the effectiveness and efficiency of projects of physical culture and sports activities, to optimize network relations.

The project approach allows you to structure a network of independent entities, primarily due to the ability to assess the priority of projects by using sets of indicators. Analysis of the literature allows us to conclude that there are a large number of approaches to evaluating projects of physical culture and sports activities. First of all, it is necessary to use the criteria for evaluating projects for compliance with their strategic guidelines laid down in the program documents. Also, according to some authors, when implementing projects related to physical culture and sports activities of the University, it is necessary to evaluate the economic efficiency. In particular, R. V. Faizullin [5] in his work proposes the following indicators for assessment: economic efficiency index of fitness and sports facilities, the level of profitability, which is a comprehensive indicator of economic efficiency of functioning of sports structures, the size of annual profits from the operation of sports facilities, load growth, i.e. the increase in the intensity of functioning of sports structures, the average filling factor.

E. N. Glubokova and I. E. Kondrakova [6], N. N. Surtayeva and O. N. Surtayeva [7], A. Yu. Mikhailishin [8] V. I. Sakharova [9], V. V. Zemlyansky, A.V. Lapshova, Yu. N.Petrov[10 ] elaborate the solution of the issues of methodological support for network modeling is in their works and describe the structure of interaction within the network model with the description of the educational program. It is important to determine the effectiveness of projects of physical culture and sports activities of the university from the position of social indicators. It is advisable to consider the following effects of network interaction $[11,12]$ :

- the degree of security of socio-demographic groups of the population (preschool children, schoolchildren, students of primary vocational education institutions, secondary schools, university students, adult working-age population, pensioners, disabled people, including disabled children) with various types of physical culture and sports facilities;

- the degree of compliance with the existing provision of various socio-demographic groups of the population with physical culture and sports facilities and the need for them;

- opportunities to meet the growing demand of the population for physical culture and sports health services on the basis of existing physical culture and sports facilities; 
- availability of conditions and opportunities for organizing physical culture and sports activities for various age groups in specific existing physical culture and sports facilities;

- degree of optimal provision of existing physical culture and sports facilities and their equipment for all types of physical culture and health and sports activities

- opportunities to combine team training and sports competitions with group and individual physical education and sports classes on special programs;

- opportunities for organizing and conducting physical culture and sports classes by families on the basis of specific physical culture and sports facilities;

- opportunities for organizing and conducting physical culture and health, sports and rehabilitation classes for disabled people, including children with disabilities, on the basis of existing physical culture and sports facilities, with their appropriate adaptation and modernization;

- opportunities for organizing leisure activities, conducting physical culture and sports activities according to special methods for the elderly on the basis of existing physical culture and sports facilities.

\section{Methods}

Methods of forming the network of the strategy of physical culture and sports activities of the University within the project approach is based on theoretical concepts presented in the first part of the thesis and analytical database obtained after the implementation of the methodology for the evaluation of projects in the strategy network management physical culture and sports activities of the University on the example of the universities of the Sverdlovsk region, the model scheme is presented in figure 1.

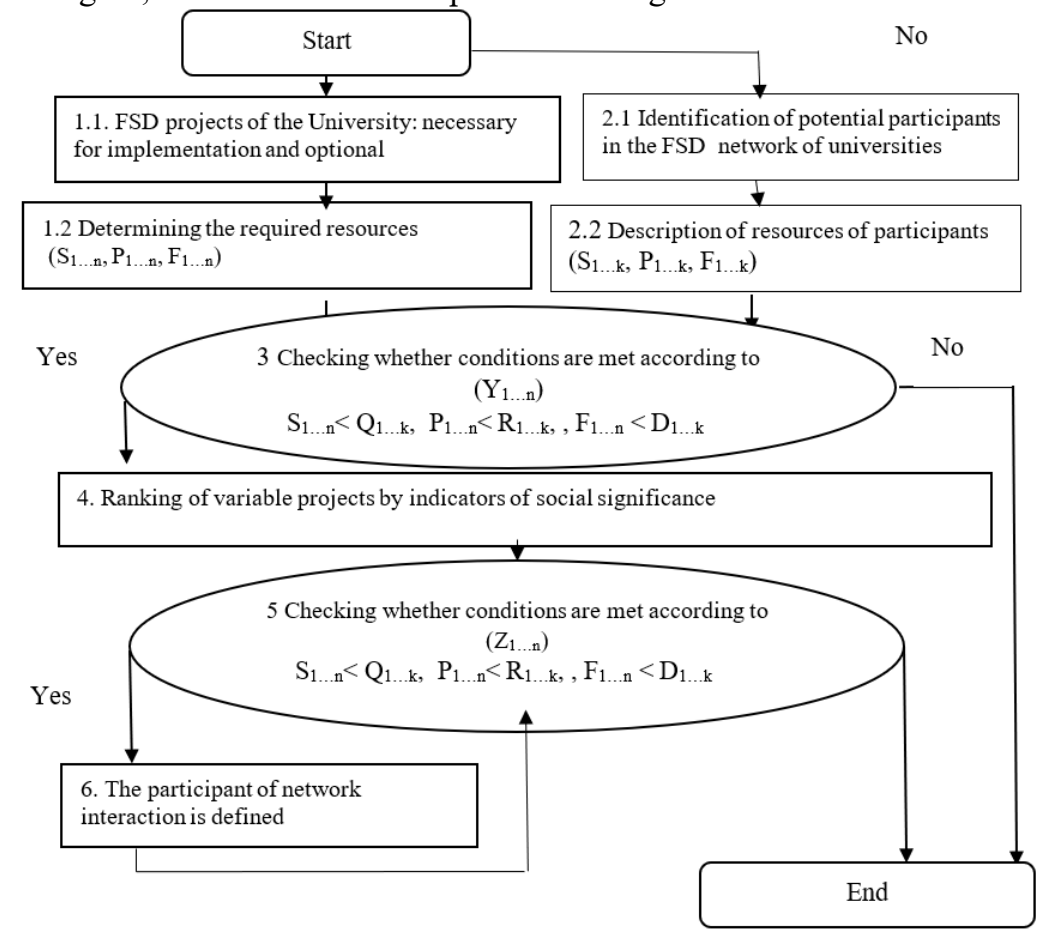

Fig. 1. Methods of network management of physical culture and sports activities of the University within the project approach 
The proposed method of network management physical culture and sports activities of the University in the project approach, which has consistently implemented the steps to define a list of prospective projects of sports activities with the evaluation resources necessary for their implementation, defining the list of participants of network communications description of the resources that they can allocate to projects of networking, selection of promising projects sports activities based on ranking in terms of the number of people included in sports activities, selection of projects on the principle of optimizing the use of resources of participants of network interaction.

\section{Results}

The implementation phases of the conceptual model of network management physical culture and sports activities of the University within the project approach allowed to define a new architecture of networking projects in the sports activities of the Universities of the Sverdlovsk region, which allows to increase the intensity of participation in projects to increase the coverage of participants and to optimize the use of resources. Further, let's consider how the network strategies of individual participants in the network interaction will change. Table 1 shows a promising matrix of network interaction in projects of physical culture and sports activities of Universities in the Sverdlovsk region.

Table 1. Perspective matrix of network interaction in projects of physical culture and sports activities of universities of the Sverdlovsk region

\begin{tabular}{|c|c|c|c|c|c|c|c|c|c|c|c|c|c|c|}
\hline & $=0$ & E $\frac{\text { z }}{0}$ & $=0$ & 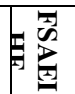 & 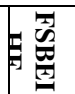 & 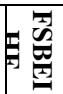 & 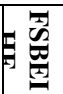 & 圈 & 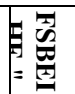 & $\begin{array}{l}0.00 \\
0.00\end{array}$ & 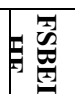 & 谓 & 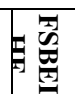 & $\begin{array}{l}0 \\
0 \\
0\end{array}$ \\
\hline FSBEI HE "USUE" & & 0 & 0 & 0 & 0 & 0 & 0 & 0 & 0 & 0 & 0 & 0 & 0 & 0 \\
\hline ANO HE "HU" & 0 & & 17 & 17 & 15 & 14 & 19 & 17 & 19 & 8 & 4 & 17 & 17 & 17 \\
\hline FSAEI HE "RSVPU" & 0 & 17 & & 22 & 15 & 14 & 19 & 22 & 19 & 8 & 4 & 22 & 22 & 22 \\
\hline FSAEI HE «UFU» & 0 & 17 & 22 & & 15 & 14 & 19 & 22 & 19 & 8 & 4 & 22 & 22 & 22 \\
\hline FSBEI HE“ESTI” & 0 & 15 & 15 & 15 & & 14 & 15 & 15 & 15 & 8 & 4 & 15 & 15 & 15 \\
\hline FSBEI HE "USC" & 0 & 14 & 14 & 14 & 14 & & 14 & 14 & 14 & 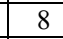 & 4 & 14 & 14 & 14 \\
\hline FSBEI HE "USMU" & 0 & 19 & 19 & 19 & 15 & 14 & & 14 & 19 & 8 & 4 & 19 & 19 & 19 \\
\hline FSBEI HE "USPU" & 0 & 17 & 22 & 22 & 15 & 14 & 14 & & 19 & 8 & 4 & 22 & 22 & 22 \\
\hline FSBEI HE "USLU" & 0 & 19 & 19 & 19 & 15 & 14 & 19 & 19 & & 0 & 4 & 19 & 19 & 19 \\
\hline FSBEI HE "USAU" & 0 & 8 & 8 & 8 & 8 & 8 & 8 & 8 & 8 & & 4 & 8 & 8 & 8 \\
\hline FSBEI HE“USUAA” & 0 & 4 & 4 & 4 & 4 & 4 & 4 & 4 & 4 & 4 & & 4 & 4 & 4 \\
\hline FSBEI HE "USMU” & 0 & 17 & 22 & 22 & 15 & 14 & 19 & 22 & 19 & 8 & 4 & & 22 & 22 \\
\hline FSBEI HE "USFEU" & 0 & 17 & 22 & 22 & 15 & 14 & 19 & 22 & 19 & 8 & 4 & 22 & & 22 \\
\hline FSBEI HE "USURT" & 0 & 17 & 22 & 22 & 15 & 14 & 19 & 22 & 19 & 8 & 4 & 22 & 22 & \\
\hline
\end{tabular}

As can be seen from Table 1, the interaction of universities in the Sverdlovsk region is much more intensive within the perspective matrix of network interaction, figure 2 . 


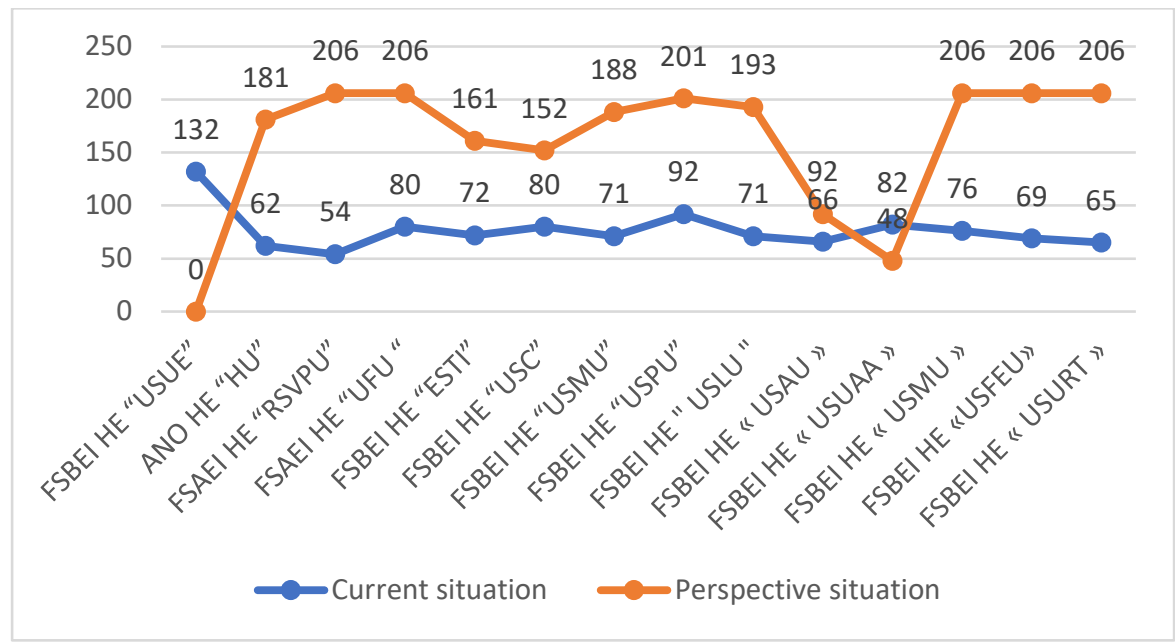

Fig. 2. Data on changes in the intensity of network interaction when implementing project approach methods in the network strategy for managing physical culture and sports activities of Universities

The total number of network interactions will increase with the project approach from 1072 to 2246 per year, or 2.1 times. Such intensity as it was according to the results of table 2 leads to an increase in participants in physical culture and sports projects from 31917 to 41151 people and more efficient use of existing resources.

\section{Conclusions}

The implementation of the project approach has led to increased coverage and an increase in the number of stable connections in the network model. The network model is being transformed from a concentric type to a distributed one by increasing the number of projects with active participation of Universities. In the scheme of network interaction, there are connections due to the need to ensure the implementation of training courses, in particular for FSBEI HE USUE connections appear to overcome resource constraints. Much more active is the inclusion of the physical culture and sports activities in projects initiated by state and municipal authorities, the corporate sector, sports organizations and Universities themselves. The number of participants actively using the network strategy has increased.

\section{References}

1. S.M. Markova, E.P. Sedykh, Science and School, 3 (2011)

2. O.V. Skopin, Modern Management Technologies, 3 (2012)

3. E.V. Nesterova, Actual problems of the humanities and natural sciences, 6 (2010)

4. A.N. Dubakin, Economic Sciences, 38 (2008)

5. R.V. Faizullin, T.N. Ivanova, Problems of Economics and Management, 11 (2015)

6. E.N. Glubokova, I.E. Kondrakova, Pedagogy in the modern world (2011)

7. N.N. Surtaeva, O.N. Surtaeva, Man and Education, 1 (2016)

8. A.Yu. Mikhailishin, Open and Distance Education, 4 (2002)

9. V.I. Sakharova, Tomsk State Pedagogical University Bulletin, 8 (2012) 
10. V.V. Zemlyansky, A.V. Lapshova, Yu.N. Petrov, XXI century: results of the past and problems of the present plus, 6 (2015)

11. V.M. Krylova, Sports Science Bulletin, 1 (2004)

12. M.A. Kocheryan, I.V. Vashlyaeva, T.V. Volovik, Theory and Practice of Physical Culture, 8 (2019) 